\title{
Blinds, Basic Education: jogo digital inclusivo para auxiliar o processo de ensino-aprendizagem das pessoas com deficiência visual
}

\author{
Kayo Costa de Santana ${ }^{1}$, Claudia Pinto Pereira ${ }^{1}$, André Luis Bitencourt \\ Fernandes ${ }^{1}$, Ana Jaíze de Oliveira Silva Santos ${ }^{1}$, Rafael da Silva Macêdo ${ }^{1}$ \\ ${ }^{1}$ Departamento de Ciências Exatas- Universidade Estadual de Feira de Santana (UEFS) \\ CEP - 44036-900 - Feira de Santana - BA - Brasil \\ kayo.santana@hotmail.com, caupinto.sena@gmail.com, deh.oo@hotmail.com, \\ a.jaize@hotmail.com, 3011rafaelegmail.com
}

\begin{abstract}
People with visual impairment need a precise look in the educational context to contemplate and stimulate their remaining skills and senses even with their specificities. Digital games can strengthen teaching and learning in relation to traditional methods, providing knowledge through the fun and allowing the autonomy and reflection of the contents approached. Therefore, this paper has as main objective, the evaluation and acceptance of Blinds, Basic Education (BBE) a multidisciplinary digital game that resembles the traditional tic-tac-toe and is able to exercise various curricular components, logical reasoning and even the perception of space and memorization.
\end{abstract}

Resumo. Pessoas com deficiência visual necessitam de um contexto educacional com um olhar apurado para suas especificidades, de modo a contemplar e estimular suas habilidades e sentidos remanescentes. A utilização de jogos digitais pode fortalecer o ensino e aprendizagem em relação aos métodos tradicionais, proporcionando o conhecimento através da brincadeira e permitindo a autonomia e reflexão dos conteúdos abordados. $O$ presente trabalho tem, portanto, como objetivo principal, a avaliação e aceitação do jogo Blinds, Basic Education (BBE) um jogo digital multidisciplinar que se assemelha ao tradicional jogo da velha e é capaz de exercitar vários componentes curriculares, o raciocínio lógico e até mesmo a percepção de espaço e memorização.

\section{Introdução}

As tecnologias da informação e comunicação (TIC) têm se tornado cada vez mais presentes no dia a dia das pessoas, fazendo parte de suas rotinas, através de recursos como computadores, tablets, smartphones, câmeras digitais, dentre outros. Esses recursos permitem, não só o armazenamento de informações, como também seu compartilhamento e disseminação. Dentre os vários ambientes em que as TICs estão inseridas, está o ambiente educacional, que vem ganhando novas possibilidades de interação e comunicação ao longo dos anos, tanto na perspectiva dos professores quanto dos alunos. 
Um dos grandes desafios da educação é o fator motivacional dos educandos para com a aprendizagem. Despertar o interesse e manter os alunos engajados em aprender os conteúdos, em meio a tantas transformações e estímulos externos, depende também da metodologia que é utilizada e da forma como estes conteúdos são apresentados. Muitos professores se esbarram nesta dificuldade e se veem sem muitas alternativas para mudar este cenário e melhorar a qualidade da aprendizagem dos educandos. Sendo assim, uma abordagem de caráter lúdico pode colaborar com o aprendizado, a revisão e a ressignificação dos conteúdos vistos em sala de aula. Dentre essas abordagens, está o uso de jogos, sejam eles manuais e/ou digitais

Segundo Moyles (2002), o uso de jogos na educação traz grandes benefícios e se mostram importantes no processo de ensino aprendizagem, pois a partir deles é possível construir e reforçar o conhecimento através de atividades lúdicas, introduzindo estímulo, motivação e interesse. Além disso, o caráter competitivo dos jogos é outro ponto que auxilia no engajamento dos educandos, pois o indivíduo, ao se deparar com a vontade de vencer, se sente bem ao atingir os objetivos propostos [Nagai e Izek, 2016].

Tendo em vista esse contexto, o BBE (Blinds Basic Education) surgiu como uma alternativa para o processo de ensino aprendizagem com a utilização de jogos digitais. Tal ferramenta consiste em um jogo de tabuleiro, multidisciplinar, com características próximas de um jogo da velha e permite exercitar vários componentes curriculares, além de trabalhar habilidades cognitivas tais como o raciocínio lógico, noção de espaço e a memorização.

Para tanto, esse artigo será dividido em mais 6 sessões, nas quais serão abordados os conceitos teóricos intrínsecos em alguns dos aspectos contemplados pela ferramenta, uma breve abordagem sobre a nova versão da ferramenta, a metodologia utilizada para a pesquisa e confecção da ferramenta, análise dos resultados obtidos, e, por fim as considerações finais sobre a ferramenta em seu estado atual.

\section{O Jogo educativo como objeto de aprendizagem}

Atualmente, diversas estratégias estão sendo adotadas por docentes em busca do aprimoramento do processo de ensino e aprendizagem, tais como metodologias ativas de aprendizagem e o uso de novos recursos tecnológicos. Dentre as mais variadas metodologias disponíveis, destaca-se a aprendizagem baseada em jogos, na qual jogos educativos são utilizados como meio principal para a construção e o aperfeiçoamento de conhecimentos dos indivíduos envolvidos.

Esta estratégia tem ganhado destaque, pois os jogos educativos apresentam características importantes para a evolução do processo de ensino e aprendizagem, independente da faixa etária do público, do conteúdo trabalhado e do grau de escolaridade em questão, propiciando "um desenvolvimento integral e dinâmico nas áreas cognitiva, afetiva, linguística, social, moral e motora, além de contribuir para a construção da autonomia, criticidade, criatividade, responsabilidade e cooperação [...]" [Moratori, 2003, p. 9]. Moratori (2003) afirma ainda que os jogos educativos devem proporcionar aos estudantes momentos desafiadores para a resolução de problemas, fazendo com que estes se sintam motivados e tenham uma participação ativa no processo educacional. Em conformidade, Monsalve (2014, p.35) afirma que os "jogos 
surgem como propostas do ensino já que fornecem aspectos práticos que o ensino tradicional de aulas expositivas não proveem, com pouca interação dos alunos".

Quando se tratam de jogos educativos, faz-se referência tanto aos jogos manuais quanto aos digitais ou computacionais, que são capazes de proporcionar $\mathrm{o}$ desenvolvimento cognitivo e momentos lúdicos de diversão em paralelo. Os digitais se evidenciam por diversos motivos, mas, principalmente, devido à capacidade de estimular o estudante a manter-se concentrado durante a sua utilização. Relacionado aos jogos digitais, Monsalve (2014, p.36) ressalva que estes "conseguem promover aspectos intelectuais e recreativos dos alunos envolvidos, além disso, podem fornecer uma estrutura para a socialização, cooperação e competitividade".

\section{Multidisciplinaridade}

As relações entre diferentes disciplinas são teoricamente organizadas em três níveis: multidisciplinaridade; interdisciplinaridade e transdisciplinaridade. Estes temas, pela sua relevância, são discutidos desde a década de 70, seja nas instituições de ensino fundamental, médio e superior [Silva e Tavares, 2005].

A multidisciplinaridade corresponde à interação entre as disciplinas, ou seja, é uma forma de estudar determinados assuntos sem a preocupação de interligá-los entre si. Neste caso, cada matéria contribui com informações pertinentes ao seu campo de conhecimento, sem que haja uma real integração entre elas [Silva e Tavares, 2005]. A interdisciplinaridade envolve mais de uma disciplina, promovendo a integração dos conteúdos de diversas áreas do conhecimento. Jean Piaget conceitua a interdisciplinaridade como a colaboração entre disciplinas de uma ciência, com interações, trocas recíprocas e enriquecimento mútuo [Piaget, 1972 apud Vicari, 2016]. E, por fim, na transdisciplinaridade, acontece uma intercomunicação entre as disciplinas, e uma nova forma de promover a integração transversal de novos saberes e conhecimentos [Bicalho e Oliveira, 2011]

A multidisciplinaridade, aliada a ludicidade no âmbito educacional, pode ser considerada mais uma estratégia para conseguir a atenção de alunos e para ressiginificar conteúdos ensinados em sala de aula. Vale ressaltar que o lúdico é um importante mecanismo que pode possibilitar o aumento do desempenho dos alunos na prática escolar, por oferecer entretenimento e diversão em atividades educacionais, possibilitando estudar brincando e brincar enquanto estuda. Segundo Souza (2009), o ato de brincar é uma linguagem fundamental na infância, constituindo-se como uma forma singular de produção e apropriação do conhecimento.

\section{Blinds, Basic Education: Nova Versão}

Na nova versão, o BBE (Blinds, Basic Education) continua com os modos que já se encontravam em funcionamento, sendo estes: o modo administrador, que permite ao usuário o cadastro de novas disciplinas; e o modo de jogo multiplayer, que possibilita ao usuário a experiência digital do jogo da velha, a partir do qual ele somente poderá marcar o espaço após responder corretamente a uma pergunta que será escolhida aleatoriamente pelo sistema, com base nas disciplinas selecionadas antes de iniciar o jogo. Vale ressaltar que, nesta versão, o BBE já possuía recursos que promoviam a 
VI Congresso Brasileiro de Informática na Educação (CBIE 2017)

Anais do XXVIII Simpósio Brasileiro de Informática na Educação (SBIE 2017)

inclusão digital de pessoas com deficiência visual, sintetizando toda a informação necessária para a interação com o ambiente.

Em sua nova versão, foram adicionadas funcionalidades, como, por exemplo, o modo single player, que permite que o usuário jogue contra o computador; um sistema de pontuação, possibilitando que o jogador acumule pontos e o sistema de ranking, que organiza os jogadores conforme sua pontuação. Além disso, para melhorar a acessibilidade, foram adicionadas teclas de atalhos, que melhoram a experiência das pessoas com deficiência visual, e a opção de diferentes temas de cores mais comuns entre este público, que oferecem um melhor contraste para pessoas com baixa visão.

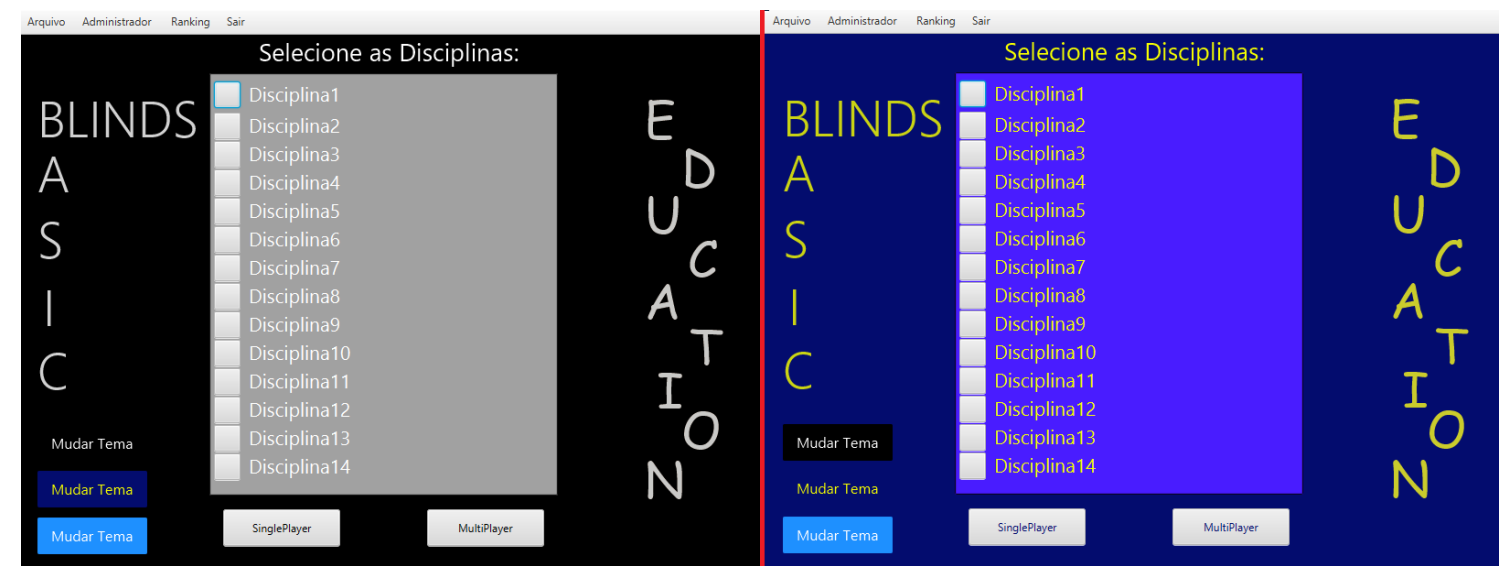

Figura 1 - Interface Inicial do BBE, em dois diferentes temas Fonte: Autor Próprio

O requisito de síntese de voz se manteve nesta versão atual, além dos ajustes mencionados, além de uma atualização na interface visual, tornando-a mais atrativa.

Na Figura 1, podem ser vistas as opções de: (a) acesso ao modo administrador, no menu superior; (b) mudança de temas, no canto inferior esquerdo; (c) seleção de disciplinas cadastradas, no centro, e (d) inicialização do modo multiplayer e singleplayer, na parte inferior.

Já na Figura 2, é possível visualizar, à esquerda, o tabuleiro do jogo e, à direita, a opção de resposta para a pergunta (quizz), que aparece após o usuário solicitar a marcação de um dos espaços disponíveis no tabuleiro. O espaço solicitado só será preenchido, caso o usuário acerte a pergunta que foi sorteada, auxiliando-o na aquisição e no exercício de diversos componentes curriculares.

O funcionamento mais detalhado do jogo, desenvolvido até então, através de um projeto de iniciação científica, financiado pela FAPESB (Fundação de Amparo à Pesquisa do Estado da Bahia), pode ser encontrado em outro trabalho que foi publicado nana XVI Escola Regional de Computação Bahia - Sergipe - Alagoas [Santana et al., 2016]. 
VI Congresso Brasileiro de Informática na Educação (CBIE 2017)

Anais do XXVIII Simpósio Brasileiro de Informática na Educação (SBIE 2017)

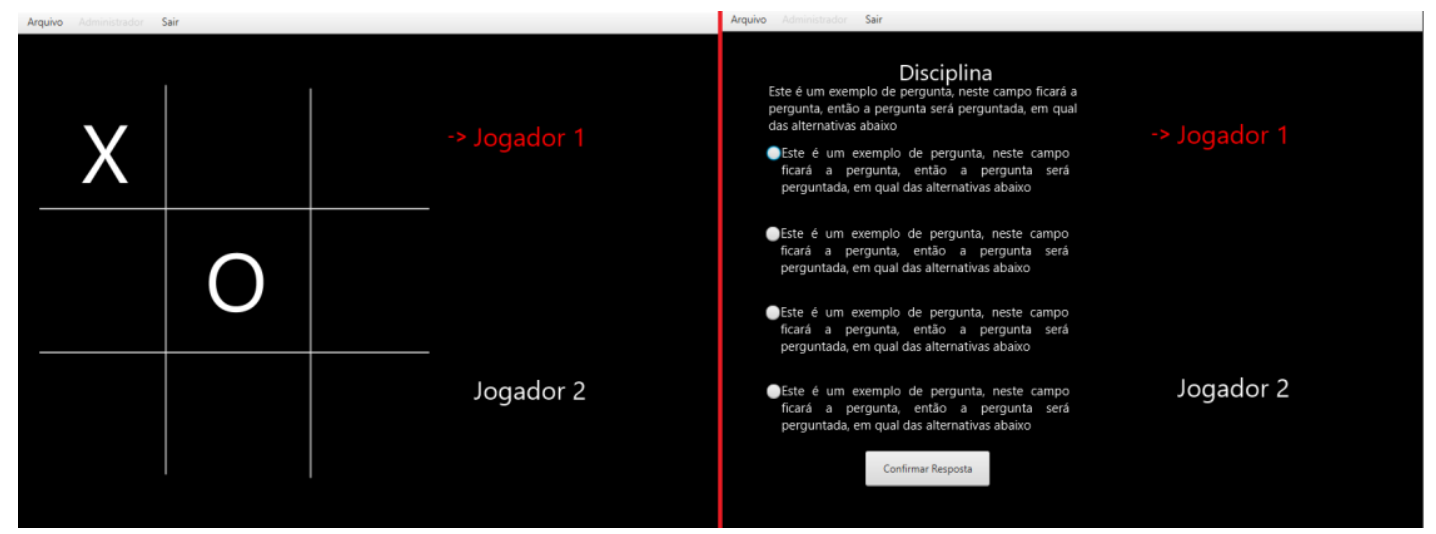

Figura 2 - Tabuleiro do BBE

Fonte: Autor Próprio

\section{Metodologia}

O objetivo desta etapa da pesquisa foi acrescentar as novas funcionalidades ao BBE (Blinds, Basic Education), validar o funcionamento de sua nova versão e verificar se, através dele, seria possível exercitar conteúdos de diferentes temáticas e conteúdos dos diferentes níveis de ensino. Além disso, também foi validado o uso da ferramenta por pessoas com deficiência visual, consolidando assim a utilização da ferramenta pelo público alvo e promovendo, como consequência, a sua inclusão sociodigital.

Em paralelo ao desenvolvimento das novas funcionalidades e da nova interface do software, o projeto de pesquisa e os questionários relacionados foram submetidos à Plataforma Brasil e aceitos pelo Comitê de Ética e Pesquisa da Universidade Estadual de Feira de Santana, através do Parecer Consubstanciado do CEP de número 2.083.580, garantido assim que a pesquisa fosse realizada conforme as resoluções 466/2012 $\mathrm{e}$ 510/2016 ${ }^{2}$ do Conselho Nacional de Saúde (Figura 3).

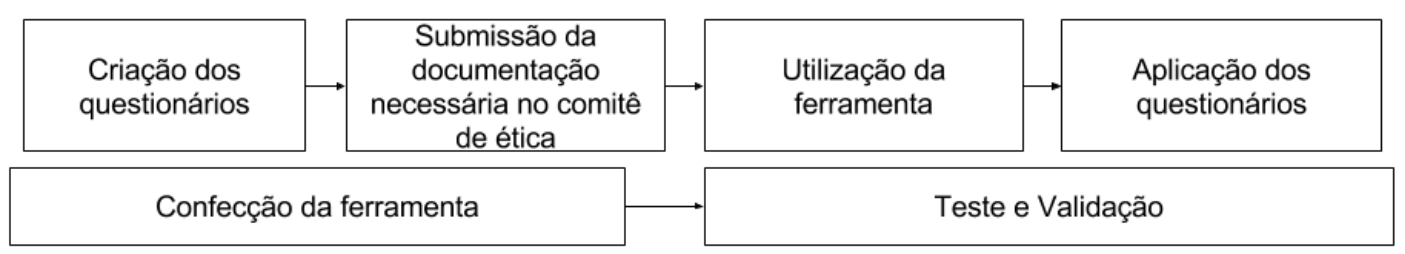

Figura 3 - Etapas de Elaboração da Pesquisa Fonte: Autor Próprio

Para a confecção da ferramenta, foram utilizados alguns conceitos e tecnologias, sendo estes: Linguagem de programação JAVA, utilização do $\mathrm{JavaFx}^{3}$ para criação da interface gráfica, sintetização de voz através do MBROLA ${ }^{4}$ e Cloud Garden ${ }^{5}$, e

\footnotetext{
${ }^{1}$ Disponível em: http://bvsms.saude.gov.br/bvs/saudelegis/cns/2013/res0466_12_12_2012.html

${ }^{2}$ Disponível em: http://conselho.saude.gov.br/resolucoes/2016/Reso510.pdf

${ }^{3}$ Mais informações sobre o JavaFX em: http://www.oracle.com/technetwork/pt/java/javafx/overview/index.html

${ }^{4}$ Mais informações sobre o MBROLA em: http://tcts.fpms.ac.be/synthesis/mbrola.html
} 
VI Congresso Brasileiro de Informática na Educação (CBIE 2017)

Anais do XXVIII Simpósio Brasileiro de Informática na Educação (SBIE 2017)

utilização de uma base de dados semiestruturada. As tecnologias escolhidas visavam, principalmente, trazer simplicidade na utilização da ferramenta pelo usuário, desde o momento de instalação, até a sua experiência.

A criação dos questionários se caracteriza como a fase de pré-teste, e a utilização da ferramenta seguida da aplicação dos questionários, como a fase de teste e validação da ferramenta. O questionário criado e tabulado com base na escala de Likert (com 5 níveis de resposta: Discordo Totalmente, Discordo Parcialmente, Indiferente, Concordo Parcialmente e Concordo Totalmente) possuía 10 perguntas objetivas e 1 pergunta subjetiva, na qual desejava-se conhecer possíveis sugestões de melhorias.

As perguntas objetivas foram organizadas com o objetivo de avaliar: (a) a ludicidade do jogo, percebendo se, não só divertia as pessoas, como também favorecia o processo de aprendizagem a partir do ensino lúdico (perguntas P1, P4, P5 e P7); (b) a multidisciplinaridade e a utilização do modo administrador, que é responsável pelo adição de novas disciplinas à base de dados do sistema (pergunta P2); (c) a exercitação de conteúdos e o desenvolvimento do raciocínio lógico, que são aspectos cognitivos que favorecem a aquisição de conhecimentos (perguntas P3, P6 e P9) e (d) o uso da ferramenta, permitindo a reflexão sobre a experiência do usuário e a possibilidade de disponibilizá-la para o público, de maneira geral (perguntas P8 e P10). O Quadro 1 apresenta as perguntas utilizadas.

Quadro 1: Legenda das perguntas utilizadas no questionário

P1- O jogo é divertido;

P2- Através do jogo é possível exercitar assuntos de diversas disciplinas;

P3- Através do jogo é possível treinar/aprender assuntos de diversas disciplinas;

P4- $O$ jogo permite que os assuntos sejam exercitados de maneira divertida;

P5- O jogo tornou o processo educacional mais interessante;

P6- A ferramenta é uma aliada para o processo de ensino-aprendizagem;

P7- O jogo pode tornar o ensino e a aprendizagem mais interessante;

P8- Eu utilizaria o jogo para exercitar algum conteúdo educacional;

P9- Através da ferramenta é possível exercitar o raciocínio lógico para vencer através do preenchimento do tabuleiro;

P10- No geral, eu considero o BBE uma ferramenta boa para auxiliar o processo de aprendizagem.

Com a pesquisa aceita e com a finalização das alterações de implementação (i.e. criação do modo singleplayer, sistema de ranking e pontuação, modo dica e alteração de toda a interface gráfica do software), iniciaram-se os testes da ferramenta, envolvendo inicialmente o grupo 1, que foi composto por 5 professores e o grupo 2, formado por 11 estudantes, ambos do curso de Engenharia de Computação da Universidade Estadual de Feira de Santana, atentando-se às suas funcionalidades e aos recursos que promovem a acessibilidade. Posteriormente, a ferramenta também foi aplicada com o grupo 3, formado por 5 pessoas com deficiência visual ( 2 deles cegos e 3 com baixa visibilidade) do Centro de Apoio ao Deficiente visual, da fundação Jonathas Telles de Carvalho, com propósito semelhante.

\footnotetext{
${ }^{5}$ Mais informações em: http://www.devmedia.com.br/artigo-java-magazine-04-javaspeech/8916
} 
VI Congresso Brasileiro de Informática na Educação (CBIE 2017)

Anais do XXVIII Simpósio Brasileiro de Informática na Educação (SBIE 2017)

\section{Discussão dos Resultados}

Os resultados obtidos através da tabulação dos questionários foram divididos entre os grupos pesquisados, para que fosse possível tanto uma análise segregada, quanto uma análise geral dos dados.

Os grupos 1 e 2, respectivamente professores e estudantes de computação, testaram todas as funcionalidades do sistema, verificando se, através do recurso de voz, era possível executar todas elas, garantindo a acessibilidade do software. Alguns dos usuários testaram a ferramenta vendados, procedimento este que não simula a experiência real de uma pessoa com deficiência visual, mas foi utilizado basicamente com o interesse de analisar o recurso de voz.

O Gráfico 1 mostra os resultados que foram obtidos através da pesquisa com o grupo 1, sinalizando que a ferramenta foi bem avaliada pelos professores, com resultados satisfatórios (i.e. Concordo Totalmente e Concordo Parcialmente) em todas as perguntas.

Gráfico 1 - Análise de dados do grupo 1

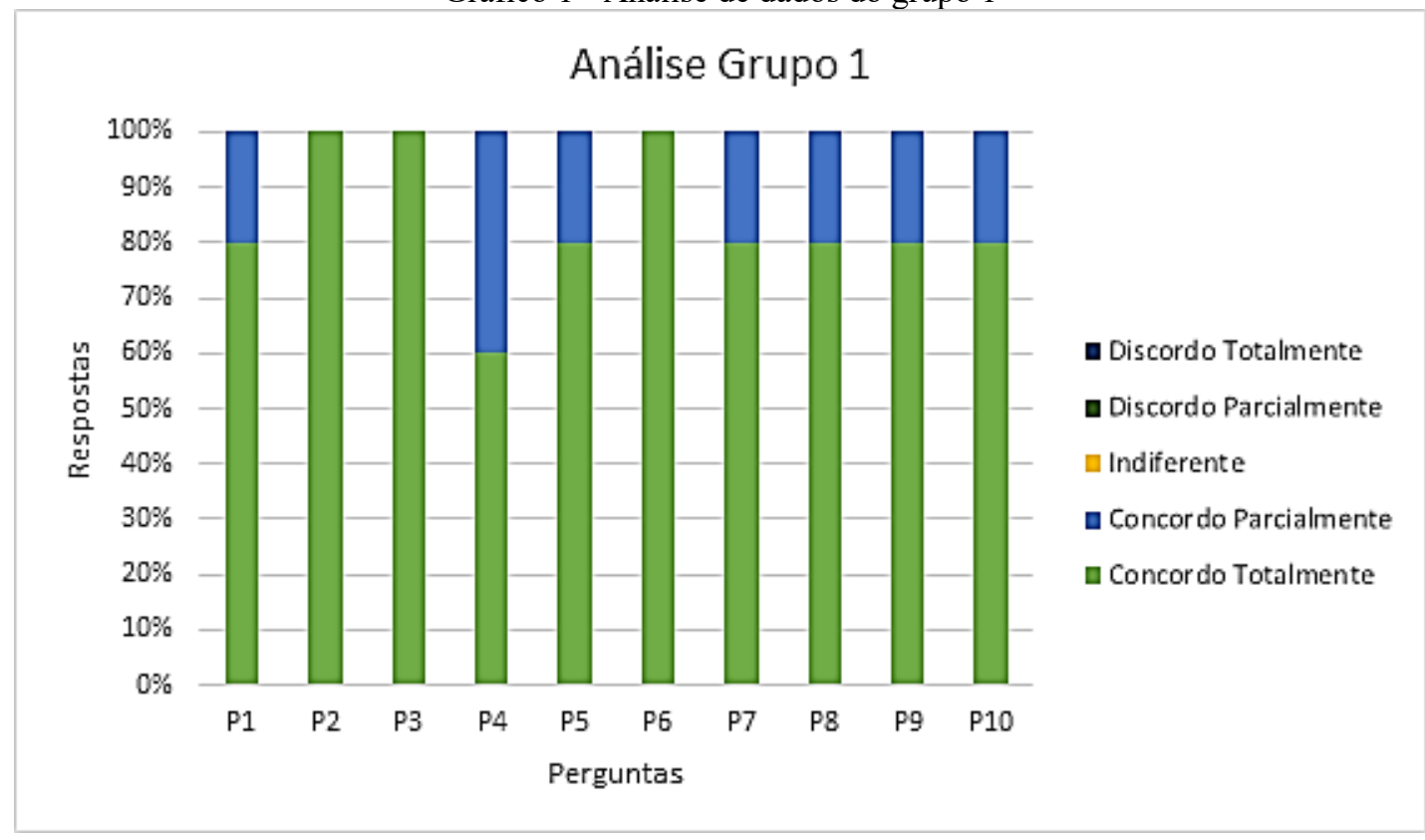

Com base nestes dados, entende-se que os professores consideraram o BBE um objeto de aprendizagem multidisciplinar que permite exercitar componentes através da ludicidade. A ferramenta recebeu como avaliação "concordo totalmente" (que equivale a uma nota máxima) maior ou igual a $60 \%$, em todas as perguntas.

Tanto no grupo 1 quanto no 2, ao se utilizar a síntese com a visão, foi percebido certo desconforto do usuário, visto que a informação gráfica/visual é absorvida de forma mais rápida do que a sonora, o que os faziam realizar a ação antes de ouvir completamente o comando. Vale salientar que é possível desativar a sintetização de voz, embora no momento inicial do teste ela se encontre ativada.

O Gráfico 2, de forma semelhante, traz os dados tabulados em relação ao grupo 2. 
VI Congresso Brasileiro de Informática na Educação (CBIE 2017)

Anais do XXVIII Simpósio Brasileiro de Informática na Educação (SBIE 2017)

Gráfico 2 - Análise de dados do grupo 2

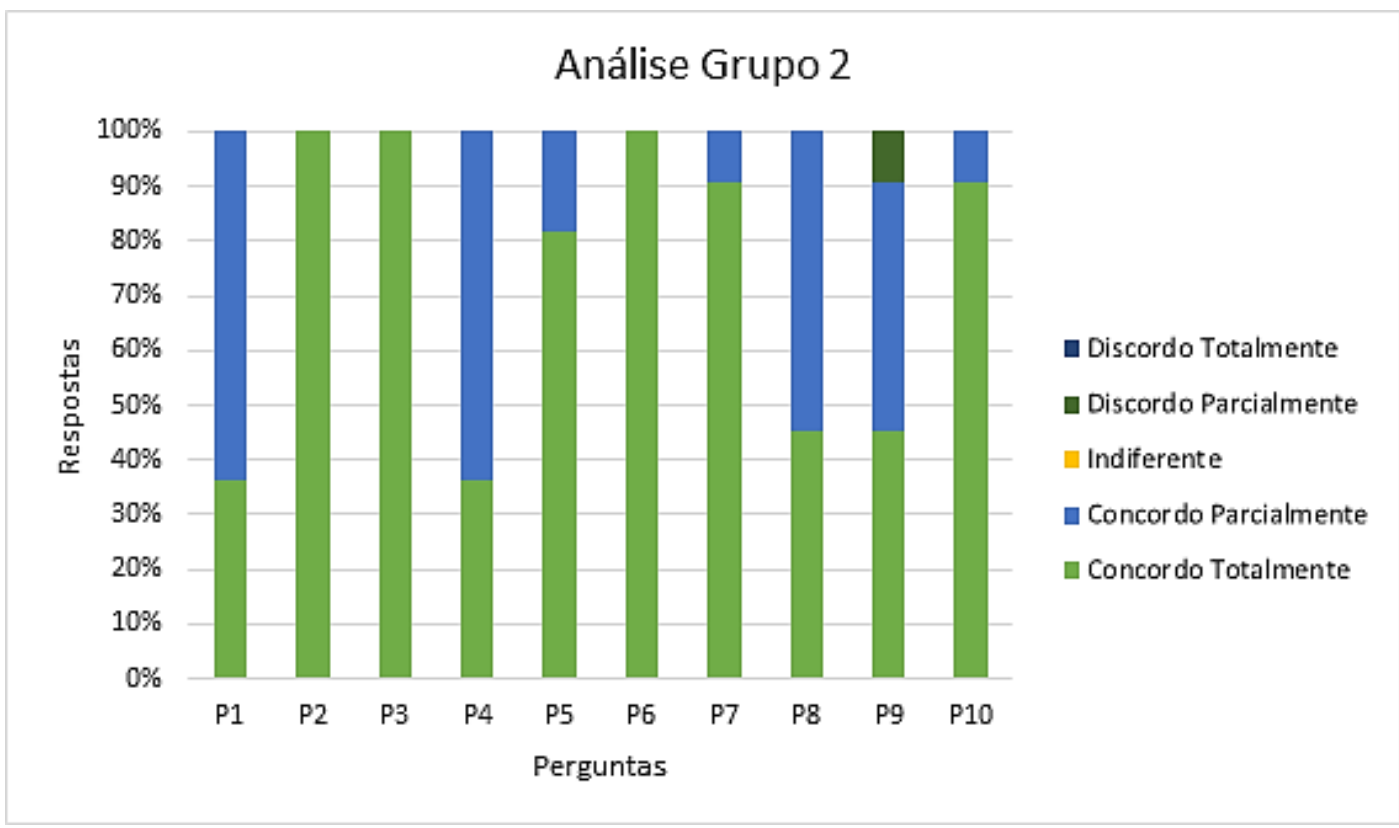

Assim como no grupo 1, a ferramenta também foi bem aceita pelos estudantes do curso (em sua maioria, "concordo totalmente" e "concordo parcialmente"), recebendo apenas uma nota discordo parcialmente, quando perguntado se o jogo contribui para o desenvolvimento do raciocínio lógico. Esta nota pode ter sido atribuída pela falta de conhecimento das estratégias por trás do jogo da velha, quando exige do usuário a marcação de espaços planejados com o objetivo de vencê-lo.

Na questão subjetiva, alguns dos participantes sugeriram algumas melhorias para a ferramenta, tais como melhor harmonia entre os elementos de interface gráfica e utilização de efeitos sonoros, como, por exemplo, aplausos, para dinamizar o jogo. Além disso, um dos professores elogiou a iniciativa, reconhecendo que existe pouca visibilidade de ferramentas que possibilitem a inclusão sociodigital da pessoa com deficiência visual e que iniciativas como essa são muito importantes para a sociedade.

Por fim, a ferramenta foi experimentada pelo grupo 3, que era o público alvo de maior interesse para essa pesquisa, por ser formado por pessoas que utilizarão futuramente a ferramenta, desfrutando dos seus recursos de acessibilidade. Esse grupo utilizou-a com orientações iniciais do pesquisador, tais como a motivação dessa proposta, a explicação das suas funcionalidades e de suas telas, e o uso dos recursos disponíveis de voz e teclas de atalho. Durante a utilização, foi perceptível a emoção esboçada em suas reações e a satisfação com o uso do objeto de aprendizagem BBE. Os resultados obtidos podem ser visualizados através do Gráfico 3.

A satisfação ao jogar e aprender com o jogo pode ser percebida com as respostas unânimes em todas as perguntas. Todo o grupo 3 concordou totalmente em todas as questões, o que ressalta a importância da ferramenta e a compreensão de suas funcionalidades. 
VI Congresso Brasileiro de Informática na Educação (CBIE 2017)

Anais do XXVIII Simpósio Brasileiro de Informática na Educação (SBIE 2017)

Gráfico 3 - Análise de dados do grupo 3

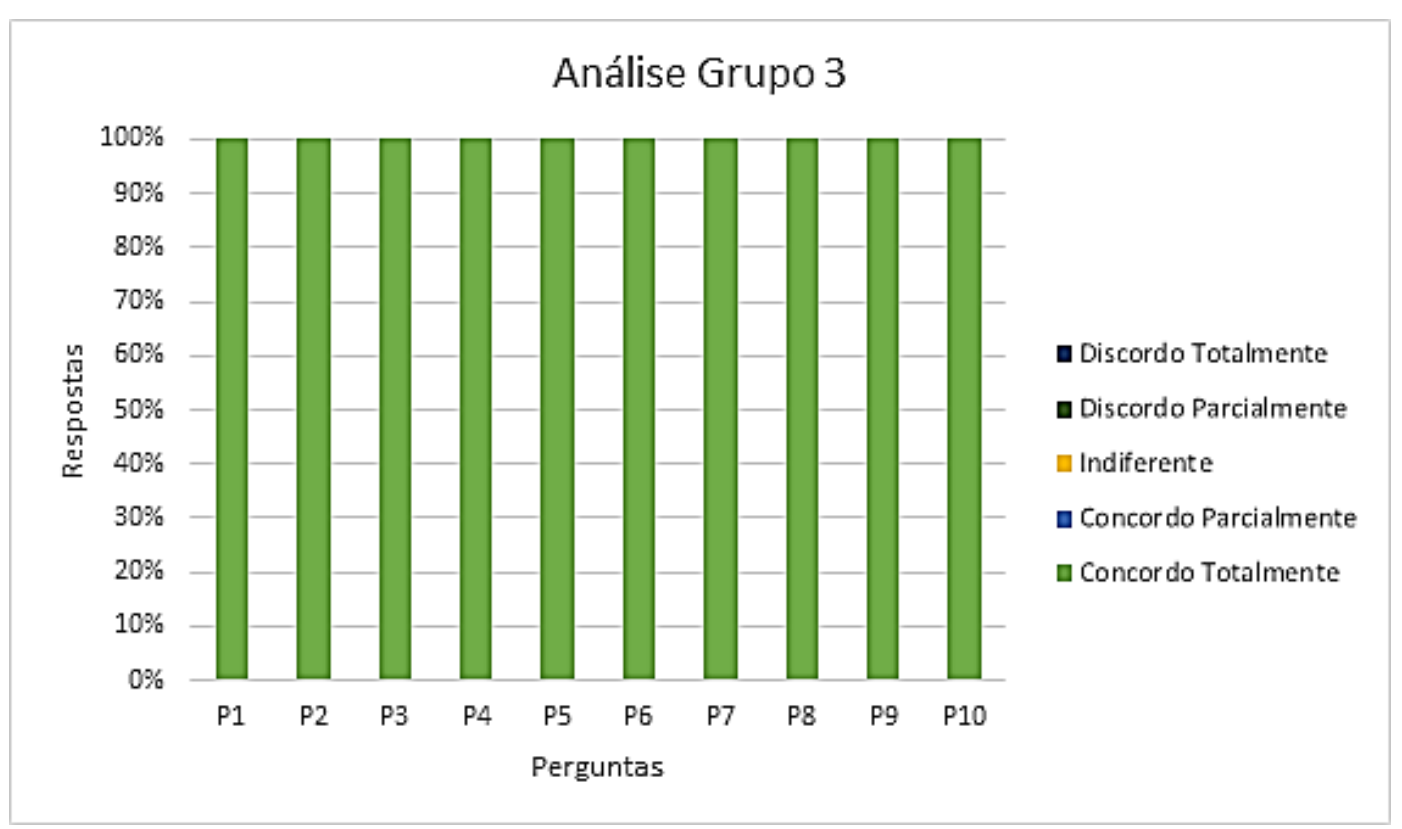

Por essa ser uma proposta inovadora que atende às necessidades do grupo (proposta tecnológica que envolve jogo da velha multidisciplinar com recurso de síntese de voz para aquisição e revisita de conhecimentos) e por permiti-los que brinquem aprendendo (jogo educacional), eles valorizaram mais o BBE do que os outros grupos. Vale ressaltar que, assim como os professores, esse grupo também apresentou a sugestão de adição de efeitos sonoros para a aplicação.

\section{Considerações Finais}

Através da pesquisa e dos resultados apresentados, é possível concluir que o BBE (Blinds, Basic Education), em sua versão atual, é uma ferramenta que pode fortalecer e contribuir com o processo de ensino-aprendizagem, em especial para as pessoas com deficiência visual. Sua característica multidisciplinar auxilia pessoas com ou sem deficiência visual na aquisição ou exercício de vários conteúdos de diferentes componentes curriculares, em diversos níveis de ensino. Sua ludicidade, com as características de jogo digital (aprendizagem baseada em jogos), torna o processo educacional mais criativo e incentivador, uma vez que "amarra" o êxito no jogo, não só à marcação adequada dos espaços (raciocínio lógico), como também às escolhas corretas das questões (prática educacional).

No geral, a ferramenta foi bem aceita pelos diversos públicos (professores e estudantes de computação e pessoas com deficiência visual), reconhecendo seu potencial educacional e a possibilidade de aprender brincando e brincar aprendendo.

A ferramenta, em sua versão atual, já pode ser disponibilizada para a utilização de diversos públicos. Entretanto, pretende-se ainda, como trabalho futuro, a inclusão de novos requisitos que a tornarão ainda mais divertida, como a sugestão de inclusão dos efeitos sonoros. Além dos resultados desta pesquisa, que visou, principalmente, a validação da ferramenta como um objeto de aprendizagem, outras posteriores, de cunho 
VI Congresso Brasileiro de Informática na Educação (CBIE 2017)

Anais do XXVIII Simpósio Brasileiro de Informática na Educação (SBIE 2017)

mais técnico, serão realizadas, validando tanto os aspectos gráficos como os vocais.

Nesta nova versão, comparada à primeira, o BBE fornece uma melhor navegabilidade e simplicidade ao usuário, sendo ele portador ou não de alguma deficiência visual. Além disso, nesta versão é possível que o usuário utilize o modo singleplayer, permitindo que ele possa ser jogado mesmo em momentos que não possua companhia.

Após disponibilização da ferramenta para o público deficiente visual, e para os espaços escolares, sejam eles regulares ou centros de apoio, a intenção é fazer um levantamento quali-quanti, ampliando os resultados aqui apresentados, como forma também de validá-los.

\section{Referências}

Bicalho, L.M., Oliveira, M. (2011) "Aspectos Conceituais da Multidisciplinaridade e da Interdisciplinaridade e a Pesquisa em Ciência da Informação". Encontros Bibli: Revista Eletrônica de Biblioteconomia e Ciência da Informação, v. 16, n. 32, p. 1-26, 2011.

Monsalve, E. S.(2014) "Uma Abordagem para Transparência Pedagógica usando Aprendizagem Baseada em Jogos." Tese de doutorado. PUC - Rio. Rio de Janeiro.

Moratori, P. B.(2003) "Por que utilizar jogos educativos no processo de ensino aprendizagem?" Universidade Federal do Rio de Janeiro. Rio de Janeiro, RJ.

Moyles, J.R. (2002) "Só brincar? O papel do brincar na educação infantil”. Porto Alegre: Artmed.

Nagai, W. A.; Izeki, C. A. (2016) "As estratégias de gamificacão da disciplina de Projeto e Análise de Algoritmos segundo o Modelo Dinâmico de Aprendizado baseado em Jogos." In: Anais dos Workshops do V Congresso Brasileiro de Informática na Educação.

Vicari, R. M. (2016) "Ciência, Praxis e Interdisciplinaridade". Computação e Interdisciplinaridade, SBC- Revista da Sociedade Brasileira de Computação, Porto Alegre/RS.

Silva, I. B, Tavares, O, A. O. (2005) "Uma pedagogia multidisciplinar, interdisciplinar ou transdisciplinar para o ensino/aprendizagem da física." Instituto Federal de Educação, Ciência e Tecnologia do Rio Grande do Norte Natal, Brasil

Souza, R. S. E. (2009) "Indisciplinaridade na educação de infância: a roda olímpica do movimento, expressão, corpo e ludicidade" Dissertação (mestrado) - Universidade Federal de Mato Grosso do Sul. Centro de Ciências Humanas e Sociais. Campo Grande, MS.

Santana, K. C.; Sena, C. P. P.; Santos, A. J. O. S.; Fernandes, A. L. B.; Macêdo, R. S. (2016) "Blinds, Basic Education: um jogo multidisciplinar para a educação básica de crianças com deficiência visual e videntes". In: Escola Regional de Computação Bahia - Alagoas - Sergipe. WInDBASE. Maceió-AL. 